\title{
A Bayesian Approach to Fault Identification in the Presence of Multi-component Degradation
}

\author{
Yufei Lin, Skaf Zakwan, and Ian Jennions \\ IVHM Centre, Cranfield University, Cranfield, MK43 OAL, UK \\ yufei.lin@cranfield.ac.uk \\ z.skaf@cranfield.ac.uk \\ i.jennions@cranfield.ac.uk
}

\begin{abstract}
Fault diagnosis typically consists of fault detection, isolation and identification. Fault detection and isolation determine the presence of a fault in a system and the location of the fault. Fault identification then aims at determining the severity level of the fault. In a practical sense, a fault is a conditional interruption of the system ability to achieve a required function under specified operating condition; degradation is the deviation of one or more characteristic parameters of the component from acceptable conditions and is often a main cause for fault generation. A fault occurs when the degradation exceeds an allowable threshold. From the point a new aircraft takes off for the first time all of its components start to degrade, and yet in almost all studies it is presumed that we can identify a single fault in isolation, i.e. without considering multi-component degradation in the system. This paper proposes a probabilistic framework to identify a single fault in an aircraft fuel system with consideration of multi-component degradation. Based on the conditional probabilities of sensor readings for a specific fault, a Bayesian method is presented to integrate distributed sensory information and calculate the likelihood of all possible fault severity levels. The proposed framework is implemented on an experimental aircraft fuel rig which illustrates the applicability of the proposed method.
\end{abstract}

\section{INTRODUCTION}

The identification of component faults is a crucial activity and therefore a significant amount of research has been undertaken on it in the past decade. As the understanding of component level faults is maturing, it is time to address how these techniques, or extension to them, could address the problem at system level. This brings with it another problem, in that all components do not degrade equally, and

Yufei Lin et al. This is an open-access article distributed under the terms of the Creative Commons Attribution 3.0 United States License, which permits unrestricted use, distribution, and reproduction in any medium, provided the original author and source are credited. the previous component analysis implicitly assumes that all other components are operating in a healthy state.

Current fault identification methods can be divided into two classes: qualitative and quantitative, as shown in Figure 1. Qualitative methods include two subcategories: graph theory and expert systems (Yang, Wang, Dong, \& Liu, 2012). Graph theory methods contain fault tree methods (William, 2010) and signed diagraph (SDG) methods (Yang, Shah, \& Xiao, 2012). Expert system methods contain conventional expert system, fuzzy expert system and belief rule-based method. Quantitative methods include two subcategories as well: model-based and data-driven. Modelbased methods (Meskin, Naderi, \& Khorasani, 2013; Poon, Konstantakopoulos, Spanos, \& Sanders, 2015) include observer/filter-based methods (Zhang X., \& Pisu P., 2014; Amoozgar, Chamseddine, \& Zhang, 2013; Caliskan, Zhang, $\mathrm{Wu}$, \& Shin, 2014), parameter estimation methods and parity relation methods. Data-driven methods contain signal processing methods (Bouzida, Touhami, Ibtiouen, Belouchrani, Fadel, \& Rezzoug, 2011), machine learning methods (Tayarani-Bathaie, Sadough Vanini, \& Khorasani, 2014; Chen, Tang, \& Chen, 2013; Saimurugan, M., \& Nithesh, R., 2016; Alaa A. J., \& Robert B., 2016), fuzzy logic methods (Ehsan \& Morteza, 2015), statistical and hybrid methods (Muralidharan \& Sugumaran, 2012; Gertler \& McAvoy, 1997; Macgregor, 1989; Jackson, Austin, Fletcher, Jessop, Liang, Pasley, Ong, Ren, Allan, Kadirkamanathan, Thompson, \& Fleming, 2005). Summarized advantages and disadvantages of current fault identification methods are shown in Table 1.

Neither qualitative methods nor quantitative methods consider multi-component degradation when identifying a single fault in a system. To the best of our knowledge, no attempt has been made to offer methodologies, tools or frameworks that can be applied to enable fault identification in a system with consideration of multi-component degradation. This paper addresses the problem of how to identify a fault at a system level and how to treat multicomponent degradation. Based on the sensor reading change 


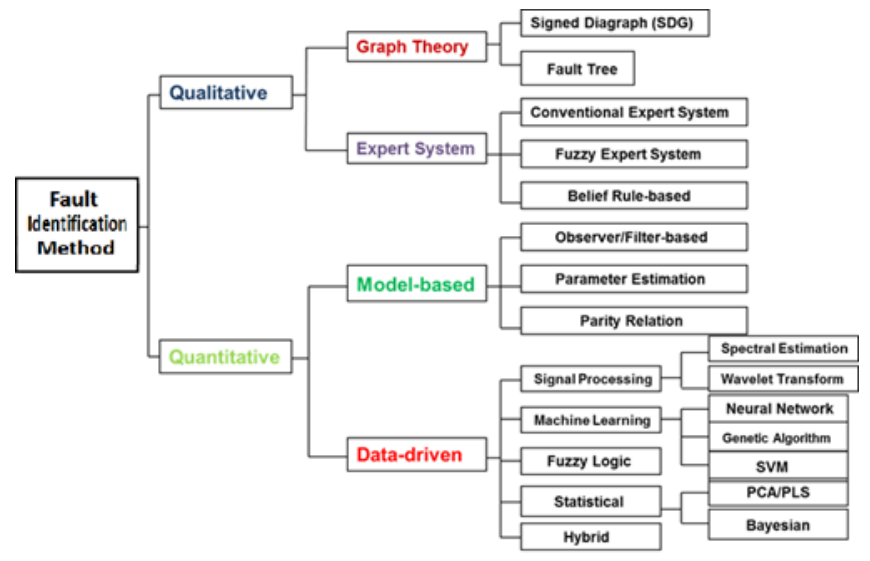

Figure 1. Classification of current fault identification methods

\begin{tabular}{c|c|c}
\hline \multirow{3}{*}{ Advantages } & Qualitative & Quantitative \\
\cline { 2 - 3 } Disadvantages & Reliability and simplicity & $\begin{array}{c}\text { Adaptable and } \\
\text { flexible }\end{array}$ \\
\cline { 2 - 3 } & $\begin{array}{c}\text { Reqle to work online } \\
\text { knowled off-line }\end{array}$ \\
\cline { 2 - 3 } & $\begin{array}{c}\text { High dependence on } \\
\text { the quantity and } \\
\text { quality of system } \\
\text { operational data }\end{array}$ \\
\hline
\end{tabular}

Table 1. Summarized advantages and disadvantages of current fault identification methods

caused by a faulty component in the presence of several degraded components in a system, we follow the idea of the Naive Bayesian method to calculate the likelihood of a certain fault severity level. The consideration of multicomponent degradation enables the fault identification result become more accurate compared with current methods.

The remainder of this paper is organized as follows. In Section 2, a brief introduction of the experimental aircraft fuel rig is given followed by a simple example that illustrates the point of considering multi-component degradation when identifying a single fault in a system. The proposed probabilistic framework including calculations of the likelihood of fault along with its severity level is presented in Section 3. Section 4 gives the validation of the proposed method through using dataset generated by the experimental aircraft fuel rig. Section 5 concludes this paper.

\section{EXPERIMENTAl Fuel Rig Description ANd Problem FORMULATION}

\subsection{Experimental Fuel Rig Description}

The experimental fuel rig test-bed (shown in Figure 2) has been developed in the IVHM Centre at Cranfield University (Niculita, Skaf, \& Jennions, 2014). It is specifically designed in order to replicate a number of component degradation faults with high accuracy and repeatability so that it can produce benchmark datasets to evaluate and assess the developed algorithms. It consists of a storage tank that contains water, a motor-driven gear pump with internal relief valve that provides volumetric flow rate, a solenoid shut-off valve, five direct-acting proportional valves (DPVs), a flow meter and five pressure sensors. The DPVs can be opened/closed to simulate degradation in the system due to: filter clogging (DPV 1), pump degradation (DPV 2), shut-off valve degradation (DPV 3), pipe leak (DPV 4), nozzle clogging (DPV 5). It can be run in a continuous circular manner. The layout of the fuel rig is shown in Figure 3.

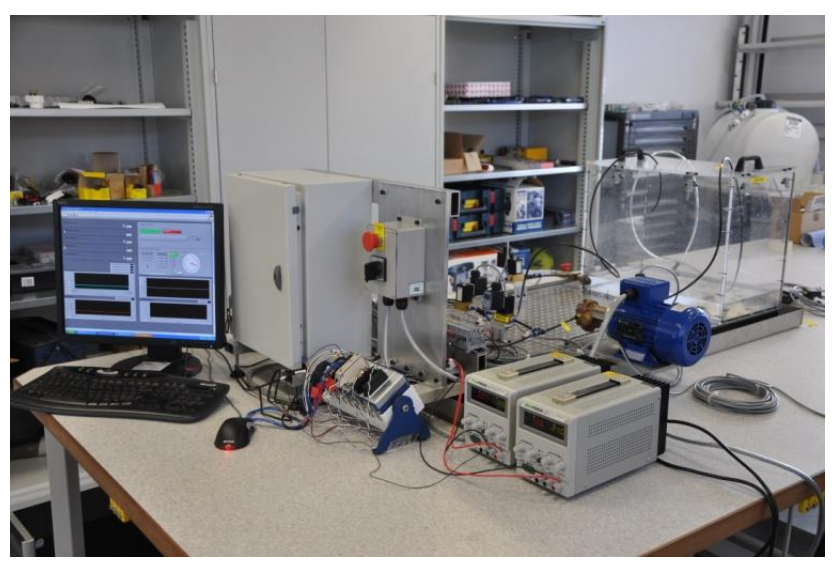

Figure 2. Photograph of the fuel rig in the IVHM Centre at Cranfield University

Pressure values (P1-P5) from different points of the system and flow rate (F-1) in the main line are taken to be the indicators of a fault. The sensors' position is shown in Figure 3. In order to collect data from the sensors, a system using National Instruments Labview instrumentation has been utilized.

\subsection{Problem Formulation}

When we are dealing with the relationship between sensor reading change and fault (caused by a faulty component), ambiguity often turns out to be a problem. That is to say, different faults cause the same sensor reading change (shown in Figure 4). Under this condition, it is very difficult for us to distinguish different faults. In order to solve this problem, current fault identification methods usually use information from nearby sensors as reinforcement, shown in Figure 5. However, when integrating information from nearby sensors, current methods commonly assume that apart from the faulty component, other components in the system are healthy, i.e. no degradation happens in other components, and the sensory information would not be influenced by other non-faulty components.

In order to illustrate this multi-component degradation, consider a simple example from the experimental fuel rig: in 


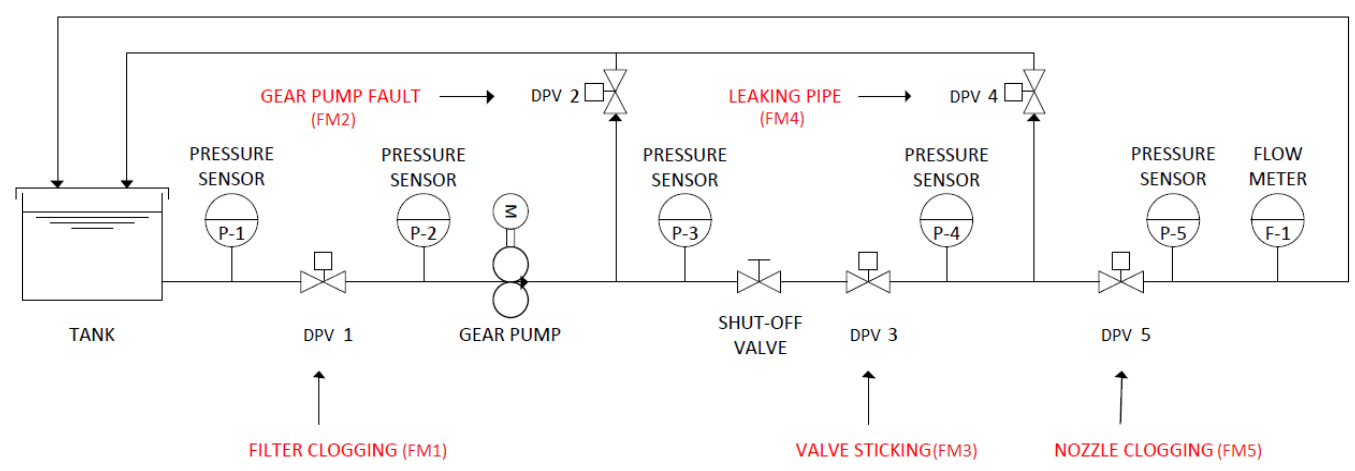

Figure 3. Layout of the experimental fuel rig

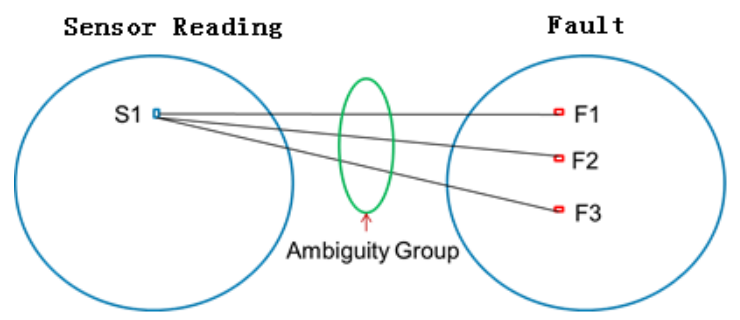

Figure 4. Ambiguity group between sensor reading change and fault

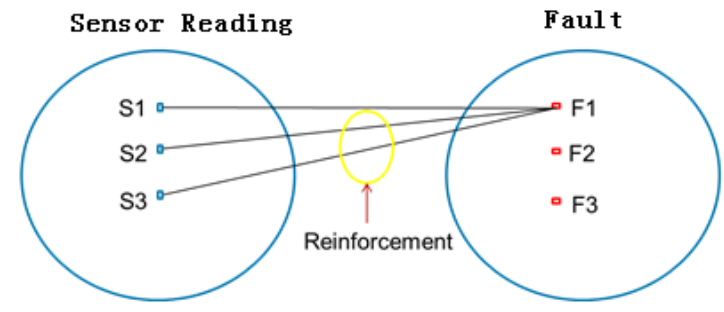

Figure 5. Integrating sensory information for reinforcement

this example, the pump is running at 400rpm, and pipe leaking is injected into the system. Figure 6 shows the reading change of pressure sensor 4 when the leak happens. The $\mathrm{X}$-axis represents the opening percentage of DPV 4 while the $\mathrm{Y}$-axis represents the reading of pressure sensor 4 . The red dotted line represents the reading with no leak. The effect of the leak is clearly seen as a reduction in the pressure measured by sensor 4 .

However, if at the same time the nozzle has $10 \%$ or $20 \%$ degradation, the reading of pressure sensor 4 will vary as shown in Figure 7.

The blue line shows the sensor reading when no degradation happens in the nozzle, while the orange and yellow line show the reading change when the nozzle has $10 \%$ and $20 \%$ degradation respectively. This variation in sensor reading is caused by the degraded nozzle and proves that the sensor reading change is influenced not only by the faulty component, but also by other degraded components. When constructing a diagnostic limit the reading of pressure sensor 4 is expected to be around 0.2 bar when the pipe leaking is $40 \%$, if there is no other degraded components in the system. However, due to the degraded nozzle, the reading of pressure sensor 4 does not reach this diagnostic threshold until around 50\%, i.e., it does not accurately reflect the severity level of the leaking. Under this condition, if we still use the sensory information without considering the influence of the degraded nozzle, we will get a misleading fault identification result. Since every component starts to degrade from the first day of its service, the above mentioned phenomenon is very likely to happen in reality. In order to solve this problem, it is necessary to consider multi-component degradation when utilizing sensory information for fault identification in a system.

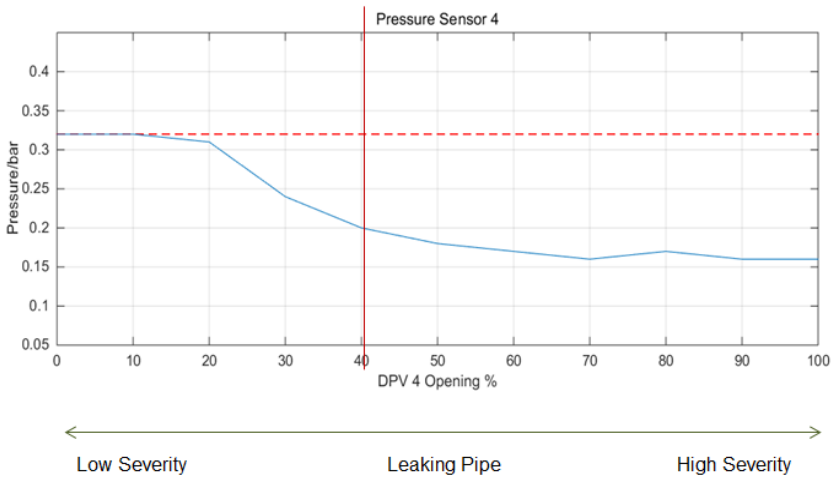

Figure 6. Reading change of pressure sensor 4 with a leaking pipe fault

\section{METHODOLOGY}

To integrate distributed sensory information in a system, we now consider the issue as to how best to represent information from a wider range of sources in one framework. Bayesian method has a great capability to tackle this sort of problem by offering a probabilistic synthesizing framework, where probability addresses degree of belief. Applications of Bayesian method have been found in the realm of image processing, medicine science, pattern recognition, engineering diagnosis and reliability analysis (Chien, Chen, \& Lin, 2002; Dey \& Stori, 2005; Mehranbod, 


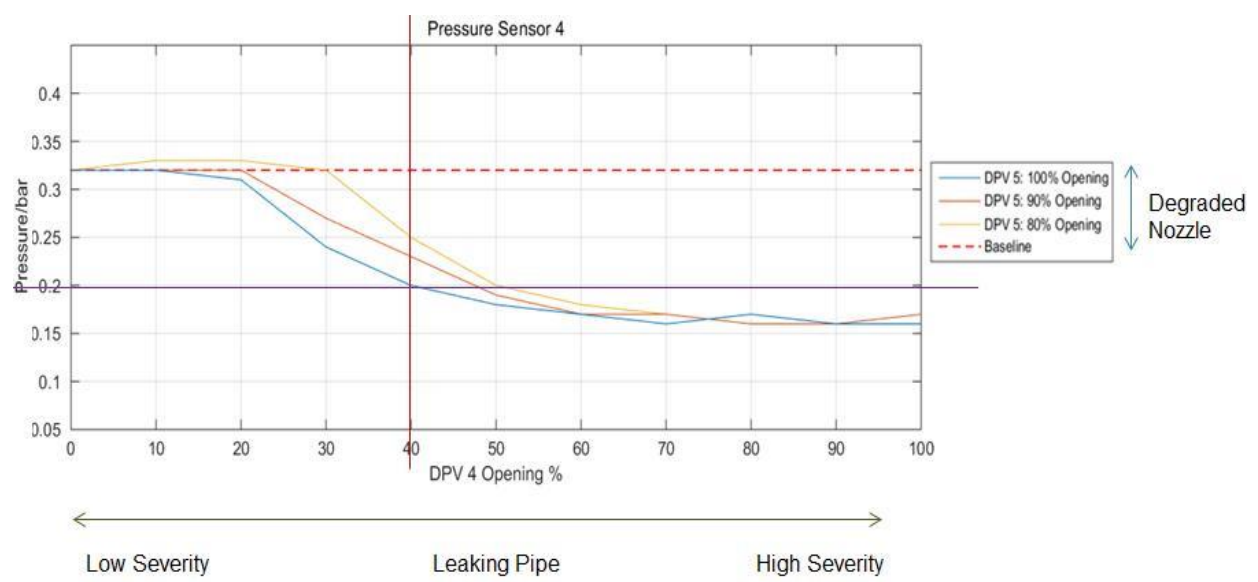

Figure 7. Reading change of pressure sensor 4 when leaking happens in the presence of a degraded nozzle

Soroush, \& Panjapornpon, 2005; Steinder \& Sethi, 2004). It is one of the most popular methods in probabilistic inferencing because of its strength to deal with uncertainties in the sampled data. The methodology used in this paper is Bayes in nature and is drawn from fundamental principle of Naïve Bayesian theory, namely, the way it relates conditional probabilities. The main difference we made here is that the conditional probability of sensor reading under a certain fault severity level is not only dependent upon the faulty component but also the degraded components in the system.

\subsection{Bayesian Method}

Based on the sensors reading $S_{1}, S_{2}, \ldots, S_{n}$, illustrated in Figure 6, the posterior probability of a certain fault $F$ along with its severity level can be written according to Bayes theory as

$$
P\left(F \mid S_{1}, S_{2}, \ldots, S_{n}\right)=\frac{L\left(S_{1}, S_{2}, \ldots, S_{n} \mid F\right) P(F)}{P\left(S_{1}, S_{2}, \ldots, S_{n}\right)}
$$

where $P\left(F \mid S_{1}, S_{2}, \ldots, S_{n}\right)$ is the posterior probability of a certain fault severity level given the current sensor reading change; $L\left(S_{1}, S_{2}, \ldots, S_{n} \mid F\right)$ is the likelihood of sensor reading conditioned on a certain fault severity level; $P(F)$ is the prior probability of a certain fault severity level $F$; and $P\left(S_{1}, S_{2}, \ldots, S_{n}\right)$ is the prior probability of sensors reading. Note that the prior probability is determined by a priori information, the posterior probability of a certain fault severity level in Eq. (1) can be denoted as:

$$
P\left(F \mid S_{1}, S_{2}, \ldots, S_{n}\right) \propto L\left(S_{1}, S_{2}, \ldots, S_{n} \mid F\right)
$$

Among all the possible fault severity levels, the one that has the largest posterior probability will be considered as the fault that causes the sensors reading change according to the Maximum Likelihood Estimate principle.
Thus, the main task for identifying the fault is to calculate the likelihood $L\left(S_{1}, S_{2}, \ldots, S_{n} \mid F\right)$ which can be computed as

$$
L\left(S_{1}, S_{2}, \ldots, S_{n} \mid F\right)=\prod_{i=1}^{n} P\left(S_{i} \mid F\right)
$$

where $P\left(S_{i} \mid F\right)$ represents the conditional probability of $i t h$ sensor's reading under a certain fault severity level, $n$ is the number of selected sensors.

As multi-component degradation is considered, the conditional probability $P\left(S_{i} \mid F\right)$ could be correctly rewritten as $P\left(S_{i} \mid F, D\right)$, where $D$ represents the set of degraded components. This addition means that the conditional probability of the sensor reading is not only dependent upon the faulty component but also the degraded components in the system. Figure 8 shows the relationship between the sensor reading, faulty component and degraded components in which $\mathrm{F}$ represents the faulty component, D represents the degraded components, $\mathrm{S}$ represents the sensor reading and $F_{n}$ represents the possible fault severity level.

Thus, from Eq. (2) and (3), we have

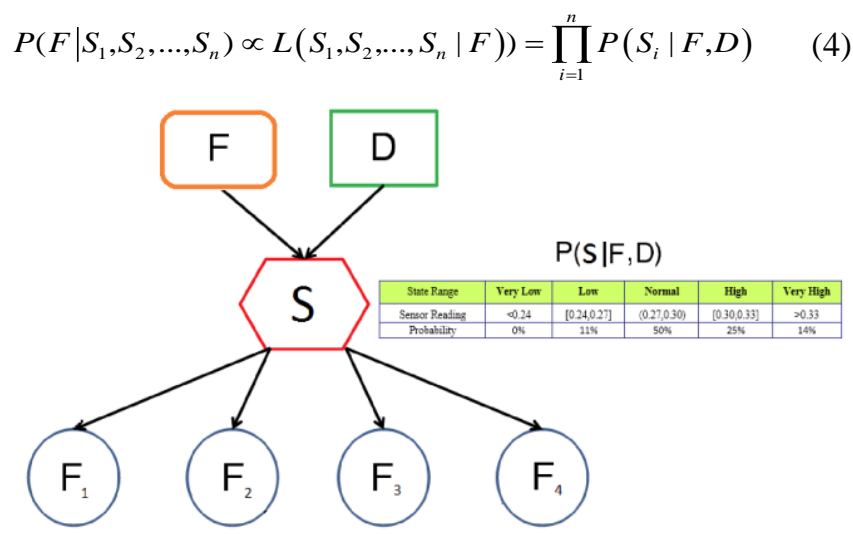

Figure 8. Relationship between the sensor reading, faulty component and degraded components 


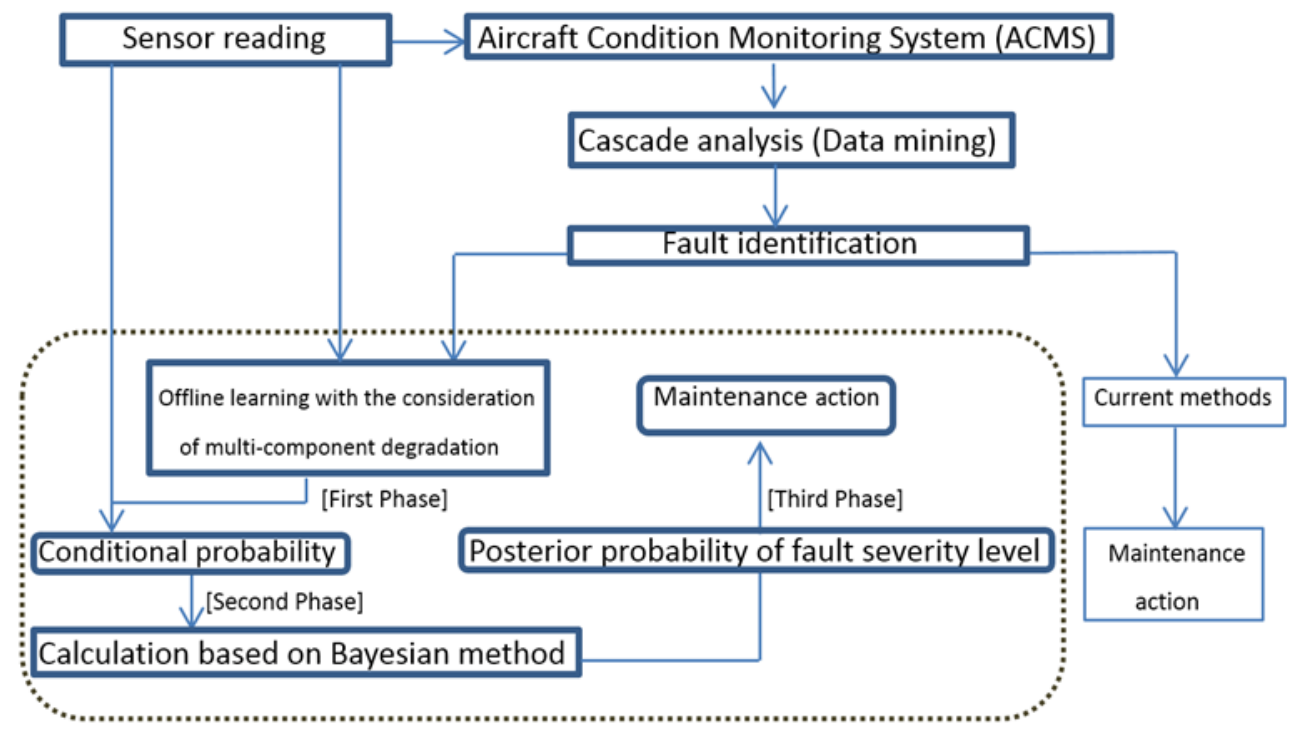

Figure 9. Workflow of the proposed method for fault identification

\subsection{Workflow}

In the case of an aircraft, according to the above strategy, the workflow of the proposed fault identification method is shown in Figure 9. The main task is within the dotted line.

When a fault has occurred, the corresponding sensor reading will be reported to the Aircraft Condition Monitoring System (ACMS) for cascade analysis (data mining). Based on historical data, the fault identification can be conducted according to the sensor reading. With the consideration of multi-component degradation, an offline learning process will be conducted to obtain the conditional probability table of sensor reading under a certain fault severity level. By comparing the current sensor reading against the conditional probability table, the conditional probability of current sensor reading can be obtained. Then based on the Bayesian method, the posterior probability of all possible fault severity levels will be calculated. Among all the possible fault severity levels, the one has the largest posterior probability will be considered as the one that causes the sensors reading change and sent to maintainers to help them arrange their maintenance actions.

\section{CASE STUdY}

In this case study, the experiment will focus on the leaking pipe mentioned in Section 2.2. The gear pump is running at 400rpm during the experiment. Since every component can have degradation, the offline learning process will run through all possible combinations of the degraded components under different leaking severity level to obtain the conditional probabilities of the sensor readings. For simplicity, all components will share the same degradation step, i.e., $10 \%$ for each step.

In order to show the offline learning process more clearly, here we select $40 \%$ as an example of the leaking severity level. When the pipe leaking is $40 \%$, the sensor reading distribution generated in the presence of no other degraded component in the system is shown in Figure 10 (the sensor readings are taken every msec over 10 seconds).

Based on the sensor reading distribution shown in Figure 10 , the conditional probability of readings from the sensors when the pipe leaking is $40 \%$ and with no other degraded component can be obtained, as shown in Table 2. For simplicity, the sensor reading is classified into five states: very high, high, normal, low and very low. The state range is chosen manually and could be adjusted.

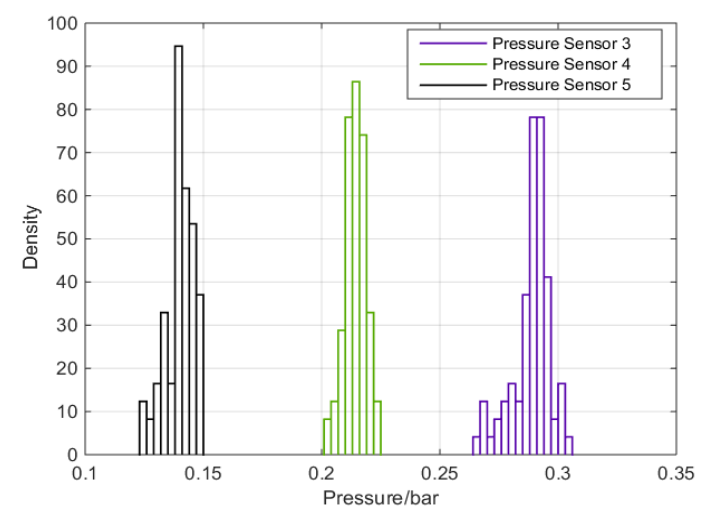

Figure 10. Sensor reading distribution when the pipe leaking is $40 \%$ and with no other degraded component

Next, keep the pipe leaking severity level at $40 \%$ and let the nozzle have $10 \%$ and $20 \%$ degradation, then the combined sensor reading distribution will vary as shown in Figure 11.

Expanding this to all causes of degradation in the system, there are altogether $34=81$ combinations of degraded component under the $40 \%$ leaking severity level, some of which are shown in Table 3. 


\begin{tabular}{c|c|c|c|c|c}
\hline $\begin{array}{c}\text { Pressure } \\
\text { Sensor 3 }\end{array}$ & $\begin{array}{c}\text { Very } \\
\text { Low }\end{array}$ & Low & Normal & High & $\begin{array}{c}\text { Very } \\
\text { High }\end{array}$ \\
\hline Reading(bar) & $<0.24$ & {$[0.24,0.27]$} & $(0.27,0.30)$ & {$[0.30,0.33]$} & $>0.33$ \\
\hline Probability & $0 \%$ & $5 \%$ & $88 \%$ & $7 \%$ & $0 \%$ \\
\hline \multicolumn{7}{|l}{} \\
\begin{tabular}{c|c|c|c|c|c} 
Pressure \\
Sensor 4
\end{tabular} & $\begin{array}{c}\text { Very } \\
\text { Low }\end{array}$ & Low & Normal & High & $\begin{array}{c}\text { Very } \\
\text { High }\end{array}$ \\
\hline Reading(bar) & $<0.13$ & {$[0.13,0.18]$} & $(0.18,0.25)$ & {$[0.25,0.3]$} & $>0.3$ \\
\hline Probability & $0 \%$ & $0 \%$ & $100 \%$ & $0 \%$ & $0 \%$ \\
\hline \multicolumn{7}{|l}{} \\
$\begin{array}{c}\text { Pressure } \\
\text { Sensor 5 }\end{array}$ & $\begin{array}{l}\text { Very } \\
\text { Low }\end{array}$ & Low & Normal & High & $\begin{array}{c}\text { Very } \\
\text { High }\end{array}$ \\
\hline Reading(bar) & $<0.11$ & {$[0.11,0.13]$} & $(0.13,0.15)$ & {$[0.15,0.17]$} & $>0.17$ \\
\hline Probability & $0 \%$ & $5 \%$ & $95 \%$ & $0 \%$ & $0 \%$ \\
\hline
\end{tabular}

Table 2. Conditional probability of readings from the sensors when the pipe leak is $40 \%$ and with no other degraded component

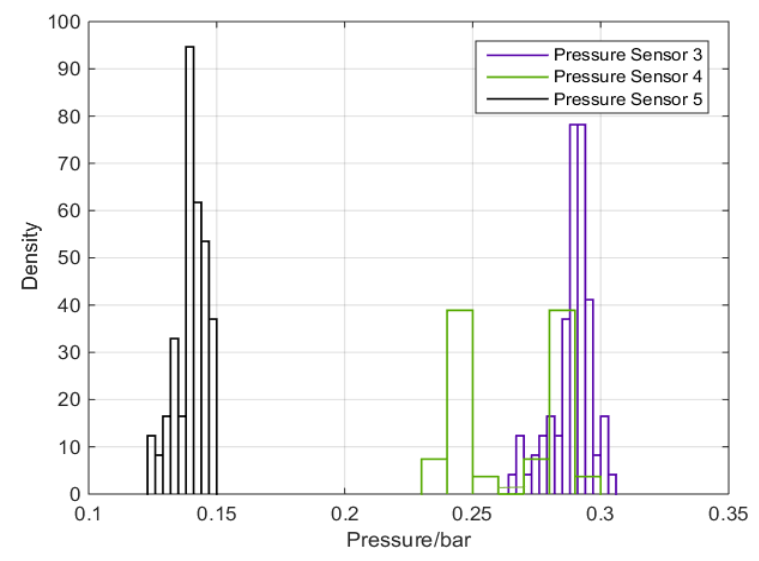

Figure 11. Sensor reading distribution when the pipe leaking is $40 \%$, nozzle degradation is $10 \%$ and $20 \%$, and with no other degraded component

\begin{tabular}{|c|c|c|c|c|c|}
\hline & Combination & $\begin{array}{c}\text { Filter } \\
\text { Clogging }\end{array}$ & $\begin{array}{c}\text { Pump } \\
\text { Degradatio } \\
\text { n }\end{array}$ & $\begin{array}{c}\text { Shut-off Valve } \\
\text { Degradation }\end{array}$ & $\begin{array}{l}\text { Nozzle } \\
\text { Clogging }\end{array}$ \\
\hline \multirow{5}{*}{ 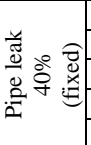 } & 1 & $0 \%$ & $0 \%$ & $0 \%$ & $0 \%$ \\
\hline & 2 & $10 \%$ & $10 \%$ & $10 \%$ & $10 \%$ \\
\hline & 3 & $20 \%$ & $20 \%$ & $20 \%$ & $20 \%$ \\
\hline & $\ldots$ & $\ldots$ & $\ldots$ & $\ldots$ & $\ldots$ \\
\hline & 81 & $20 \%$ & $20 \%$ & $20 \%$ & $10 \%$ \\
\hline
\end{tabular}

Table 3. Combinations of the degraded components when the pipe leaking is $40 \%$

After running through all possible combinations of the degraded components under the $40 \%$ leaking severity level, the cumulative sensor reading distribution can be obtained, as shown in Figure 12.

It can be observed from Figures 10 and 12 that there exists a very big difference between the sensor reading distribution generated with and without the consideration of multicomponent degradation. The sensor reading distribution generated under the consideration of multi-component degradation covers a much wider range than the sensor reading distribution generated without consideration of multi-component degradation.

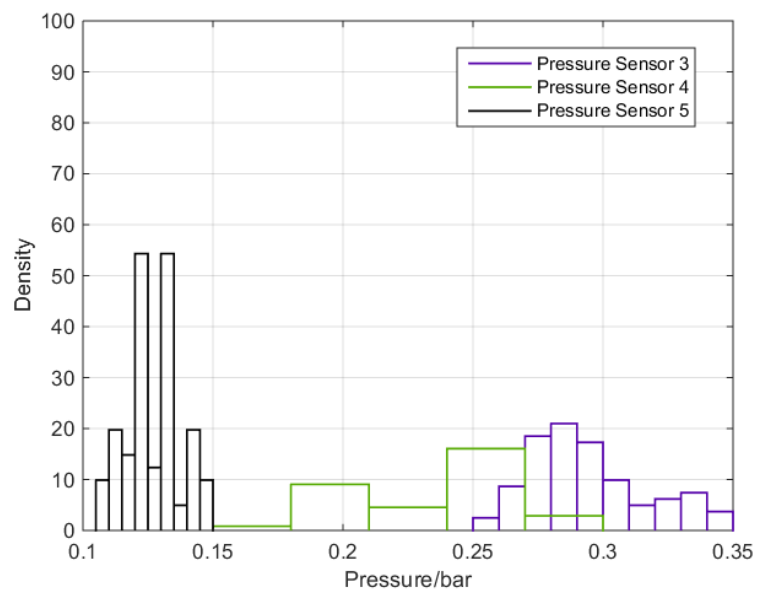

Figure 12. Sensor reading distribution when the pipe leaking is $40 \%$ and all other components in the system can have degradations

Based on the sensor reading distribution shown in Figure 12, the conditional probability of readings from the sensors when the pipe leaking is $40 \%$ can be obtained, as shown in Table 4. Note that the pressure range for low, normal, high, etc, have not been altered.

\begin{tabular}{|c|c|c|c|c|c|}
\hline $\begin{array}{l}\text { Pressure } \\
\text { Sensor } 3 \\
\end{array}$ & $\begin{array}{l}\text { Very } \\
\text { Low }\end{array}$ & Low & Normal & High & $\begin{array}{l}\text { Very } \\
\text { High }\end{array}$ \\
\hline Reading(bar) & $<0.24$ & {$[0.24,0.27]$} & $(0.27,0.30)$ & {$[0.30,0.33]$} & $>0.33$ \\
\hline Probability & $0 \%$ & $11 \%$ & $50 \%$ & $25 \%$ & $14 \%$ \\
\hline $\begin{array}{l}\text { Pressure } \\
\text { Sensor } 4\end{array}$ & $\begin{array}{l}\text { Very } \\
\text { Low }\end{array}$ & Low & Normal & High & $\begin{array}{l}\text { Very } \\
\text { High }\end{array}$ \\
\hline Reading(bar) & $<0.13$ & {$[0.13,0.18]$} & $(0.18,0.25)$ & {$[0.25,0.3]$} & $>0.3$ \\
\hline Probability & $0 \%$ & $7 \%$ & $63 \%$ & $30 \%$ & $0 \%$ \\
\hline $\begin{array}{l}\text { Pressure } \\
\text { Sensor } 5\end{array}$ & $\begin{array}{l}\text { Very } \\
\text { Low }\end{array}$ & Low & Normal & High & $\begin{array}{l}\text { Very } \\
\text { High } \\
\end{array}$ \\
\hline Reading(bar) & $<0.11$ & {$[0.11,0.13]$} & $(0.13,0.15)$ & {$[0.15,0.17]$} & $>0.17$ \\
\hline Probability & $5 \%$ & $50 \%$ & $45 \%$ & $0 \%$ & $0 \%$ \\
\hline
\end{tabular}

Table 4. Conditional probability of readings from the sensors when the pipe leak is $40 \%$ and all other components in the system can have degradations

Now let's examine 3 sets of readings from the sensors, given as examples in Table 5 (Example 1-3), to test the proposed method and compare the result with the classic Bayesian method.

Based on the conditional probabilities in Table $2 \& 4$, and similar tables for $30 \%$ and $50 \%$ leaking (not shown), the conditional probabilities of sensor reading in Example 1 can be obtained, as shown in Table 6.

Based on the conditional probabilities of the sensor readings from Table 6 , the likelihood of each possible leaking 
severity level can be calculated. According to the discussion in Section 3,

$$
P\left(L_{S L} \mid S_{3}, S_{4}, S_{5}\right) \propto \prod_{i=3}^{5} P\left(S_{i} \mid L_{S L}, D\right)
$$

where $L_{S L}$ represents the leaking severity level, $P\left(L_{S L} \mid S_{3}, S_{4}, S_{5}\right)$ represents the likelihood of leaking severity level based on current sensor reading, and $P\left(S_{i} \mid L_{S L}, D\right)$ represents the conditional probability of the sensor reading obtained with the consideration of multicomponent degradation. Compared with the proposed method, the classic Bayesian method would express the likelihood of leaking severity level as:

$$
P\left(L_{S L} \mid S_{3}, S_{4}, S_{5}\right) \propto \prod_{i=3}^{5} P\left(S_{i} \mid L_{S L}\right)
$$

where $P\left(S_{i} \mid L_{S L}\right)$ represents the conditional probability of the sensor reading obtained when the pipe is leaking and with no other degraded component.

After this calculation, the severity level with the largest likelihood will be considered as the one that causes the sensor reading change. Results from the proposed method and classic Bayesian method are compared and shown in Table 7, from which we can observe that due to the influence from degraded nozzle, the fault identification result from classic Bayesian method in Example 1 tends to underestimate the leaking severity level while the proposed method can correctly identify the severity level.

For Example 2, due to the influence from degraded filter and pump, the leaking severity level obtained from classic Bayesian method is $50 \%$, which is an overestimation of the actual leaking severity level. The identification result from the proposed method is $40 \%$, which is consistent with the actual leaking severity level. For Example 3, the leaking severity level obtained from classic Bayesian method and the proposed method are both $40 \%$.

So after running through all sets of readings generated under the $40 \%$ leaking severity level, the correct identification rate of classic Bayesian method is only $63.7 \%$ owing to the ignorance of multi-component degradation, which is much lower than the correct identification rate of proposed method, which is $85.3 \%$.

Following the same procedure, the correct identification rate of classic Bayesian method and proposed method under other leaking severity levels can be obtained, as shown in Figure 13. It is worth noting here that because there exist some noise in the sensor readings, the manually chosen state range of sensor reading has some effect on the correct identification rate, i.e., the correct identification rate can vary slightly if the state range is changed.

It can be observed that when the pipe leaking is below $60 \%$, the proposed method could remarkably reduce the risk of misjudgment of fault severity level compared with classic Bayesian method. But when the pipe leaking is $60 \%$ and

\begin{tabular}{c|c|c|c|c|c|c|c|c}
\hline Example & $\begin{array}{c}\text { Actual leaking } \\
\text { severity level }\end{array}$ & $\begin{array}{c}\text { Degradation } \\
\text { level of nozzle }\end{array}$ & $\begin{array}{c}\text { Degradation level } \\
\text { of shut-off valve }\end{array}$ & $\begin{array}{c}\text { Degradation } \\
\text { level of pump }\end{array}$ & $\begin{array}{c}\text { Degradation } \\
\text { level of filter }\end{array}$ & $\begin{array}{c}\text { Sensor 3 } \\
\text { reading }\end{array}$ & $\begin{array}{c}\text { Sensor 4 } \\
\text { reading }\end{array}$ & $\begin{array}{c}\text { Sensor } 5 \\
\text { reading }\end{array}$ \\
\hline 1 & $40 \%$ & $20 \%$ & $0 \%$ & $0 \%$ & $0 \%$ & $0.29 \mathrm{bar}$ & $0.27 \mathrm{bar}$ & $0.14 \mathrm{bar}$ \\
\hline 2 & $40 \%$ & $0 \%$ & $0 \%$ & $20 \%$ & $10 \%$ & $0.25 \mathrm{bar}$ & $0.19 \mathrm{bar}$ & $0.12 \mathrm{bar}$ \\
\hline 3 & $40 \%$ & $0 \%$ & $10 \%$ & $10 \%$ & $10 \%$ & $0.29 \mathrm{bar}$ & $0.21 \mathrm{bar}$ & $0.14 \mathrm{bar}$ \\
\hline
\end{tabular}

Table 5. Several examples from testing process

\begin{tabular}{c|c|c|c|c|c|c}
\hline & \multicolumn{2}{|c|}{ Pipe leaking 40\% with no other degradation } & \multicolumn{2}{c}{ Pipe leaking 40\% with multi-degradation } \\
\hline $\begin{array}{c}\text { Possible leaking } \\
\text { severity level }\end{array}$ & $P\left(S_{3} \mid L_{S L}\right)$ & $P\left(S_{4} \mid L_{S L}\right)$ & $P\left(S_{5} \mid L_{S L}\right)$ & $P\left(S_{3} \mid L_{S L}, D\right)$ & $P\left(S_{4} \mid L_{S L}, D\right)$ & $P\left(S_{5} \mid L_{S L}, D\right)$ \\
\hline $30 \%$ & $12 \%$ & $100 \%$ & $5 \%$ & $20 \%$ & $60 \%$ & $25 \%$ \\
\hline $40 \%$ & $88 \%$ & $0 \%$ & $95 \%$ & $50 \%$ & $30 \%$ & $45 \%$ \\
\hline $50 \%$ & $0 \%$ & $0 \%$ & $0 \%$ & $20 \%$ & $0 \%$ & $0 \%$ \\
\hline
\end{tabular}

Table 6. Conditional probability of the sensor reading 


\begin{tabular}{c|c|c|c|c|c|c|c}
\hline Example & $\begin{array}{c}\text { Actual leaking } \\
\text { severity level }\end{array}$ & $\begin{array}{c}\text { Degradation } \\
\text { level of nozzle }\end{array}$ & $\begin{array}{c}\text { Degradation level } \\
\text { of shut-off valve }\end{array}$ & $\begin{array}{c}\text { Degradation } \\
\text { level of pump }\end{array}$ & $\begin{array}{c}\text { Degradation } \\
\text { level of filter }\end{array}$ & $\begin{array}{c}\text { Leaking severity level obtained by } \\
\text { classic Bayesian method }\end{array}$ & $\begin{array}{c}\text { Leaking severity level obtained by } \\
\text { proposed method }\end{array}$ \\
\hline 1 & $40 \%$ & $20 \%$ & $0 \%$ & $0 \%$ & $0 \%$ & $30 \%$ & $40 \%$ \\
\hline 2 & $40 \%$ & $0 \%$ & $0 \%$ & $20 \%$ & $10 \%$ & $50 \%$ & $40 \%$ \\
\hline 3 & $40 \%$ & $0 \%$ & $10 \%$ & $10 \%$ & $10 \%$ & $40 \%$ & $40 \%$ \\
\hline
\end{tabular}

Table 7. Fault identification results (classic Bayesian method vs. proposed method)

beyond (i.e. severe), performances of classic Bayesian method and proposed method are nearly the same. This suggests that the leaking fault has become so serious that the other degradations do not significantly affect the results.

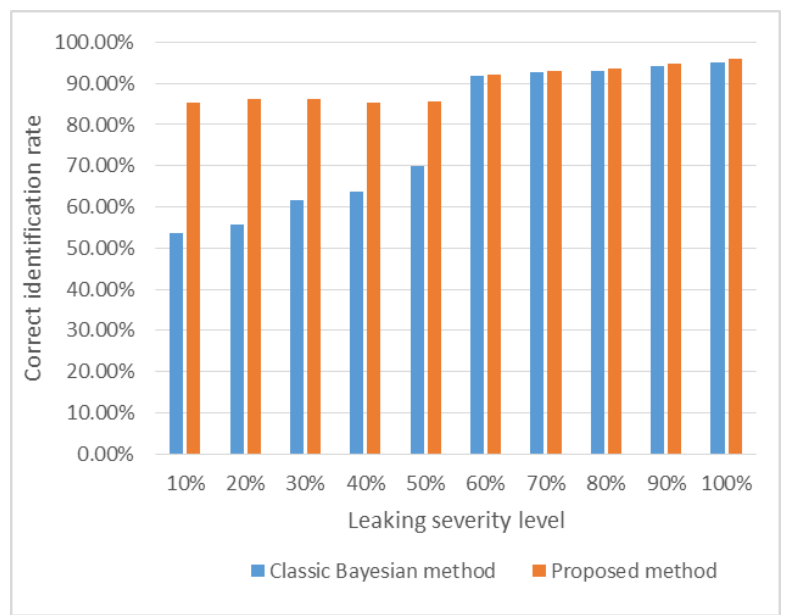

Figure 13. Correct identification rate (classic Bayesian method vs. proposed method)

\section{CONCLUSION}

For fault identification with the consideration of multicomponent degradation, a probabilistic framework based on the Bayesian method is proposed. With the consideration of multi-component degradation, conditional probabilities of sensor readings are first obtained through an offline learning process and then integrated by the proposed method. This makes the calculation of posterior probability of fault severity levels more accurate and therefore helps the maintainers make more informed decisions.

The key point of the proposed framework is the capability to identify the severity level of a fault by integrating distributed sensory information with the consideration of multi-component degradation. Compared with current fault identification methods, which commonly ignore multicomponent degradation, the proposed framework is able to give a more accurate result which has been validated through using an experimental aircraft fuel rig.
It is worth noting here that because we do not consider the sensor degradation in this work, future work could be done to make the fault identification results more accurate.

\section{ACKNOWLEDGEMENT}

The first author would like to thank the Chinese government scholarship (CSC) for their financial support.

\section{REFERENCES}

Alaa A. J., \& Robert B. (2016). Fault diagnosis of industrial robot bearings based on discrete wavelet transform and artificial neural network. International Journal of Prognostics and Health Management, ISSN 2153-2648, 2016017.

Amoozgar M. H., Chamseddine A., \& Zhang Y. M. (2013). Experimental test of a two-stage Kalman filter for actuator fault detection and diagnosis of an unmanned quadrotor helicopter. Journal of Intelligent \& Robotic Systems, vol. 70, issue 1, pp. 107-117.

Bouzida A., Touhami O., Ibtiouen R., Belouchrani A., Fadel M., \& Rezzoug A. (2011). Fault diagnosis in industrial induction machines through discrete wavelet transform. IEEE Trans. Ind. Electron., vol. 58, no. 9, pp. 43854395.

Caliskan F., Zhang Y., Wu N. Eva, \& Shin Jong-Yeob (2014). Actuator fault diagnosis in a Boeing 747 model via adaptive modified two-stage Kalman filter. International Journal of Aerospace Engineering, vol. 2014.

Chen F., Tang B. P., \& Chen R. X. (2013). A novel fault diagnosis model for gearbox based on wavelet support vector machine with immune genetic algorithm. Measurement, vol. 46, issue 1, pp. 220-232.

Chien, C. F., Chen, S. L., \& Lin, Y. S. (2002). Using Bayesian network for fault location on distribution feeder. IEEE Transactions on Power Delivery, vol. 17(13), pp. 785-793.

Dey S., \& Stori J. A. (2005). A Bayesian network approach to root cause diagnosis of process variations. International Journal of Machine Tools, vol. 45(1), pp. 75-91.

Ehsan M., \& Morteza M. (2015). A fuzzy-based gas turbine fault detection and identification system for full and 
part-load performance deterioration. Aerospace Science and Technology, vol. 46, pp. 82-93.

Gertler J., \& McAvoy T. J. (1997). Principal component analysis and parity relations-strong duality. IFAC Safe Process, vol. 2, pp. 837-842.

Jackson T., Austin J., Fletcher M., Jessop M., Liang B., Pasley A., Ong M., Ren X., Allan G., Kadirkamanathan V., Thompson H. A., \& Fleming P. J. (2005). Distributed health monitoring for aero-engines on the GRID: DAME. Proceeding of IEEE Aerospace Conference, pp. 3738-3747.

Macgregor J. (1989). Multivariate Statistical Methods for Monitoring Large Datasets from Chemical Processes. AIChE meeting, San Francisco.

Mehranbod N., Soroush, M., \& Panjapornpon, C. (2005). A method of sensor fault detection and identification. Journal of Process Control, vol. 15(3), pp. 321-339.

Meskin N., Naderi E., \& Khorasani K. (2013). A multiple model-based approach for fault diagnosis of jet engines. IEEE Transactions on Control Systems Technology, vol. 21, issue 1, pp. 254-262.

Muralidharan V., \& Sugumaran V. (2012). A comparative study of Naïve Bayes classifier and Bayes net classifier for fault diagnosis of monoblock centrifugal pump using wavelet analysis. Applied Soft Computing, vol. 12 , issue 8, pp. 2023-2029.

Niculita O., Skaf Z., \& Jennions, I. K. (2014). The application of Bayesian change point detection in UAV fuel systems. 3rd International Conference on Through-life Engineering Services.

Poon, J., Konstantakopoulos I.C., Spanos C., \& Sanders S. R. (2015). Real-time model-based fault diagnosis for switching power converters. Applied power electronics conference and exposition (APEC), IEEE, March 1519.

Saimurugan, M., \& Nithesh, R. (2016). Intelligent fault diagnosis model for rotating machinery based on fusion of sound signals. International Journal of Prognostics and Health Management, ISSN 2153-2648, 2016018.

Steinder M., \& Sethi A. S. (2004). Probabilistic fault localization in communication systems using belief networks. IEEE/ACM Transactions on Networking, vol. 12(5), pp. 809-822.

Tayarani-Bathaie S. S, Sadough Vanini Z.N., \& Khorasani K. (2014). Dynamic neural network-based fault diagnosis of gas turbine engines. Neurocomputing, vol. 125, pp. 153-165.

William, V. (2010). Fault tree handbook with aerospace applications. NASA, Rev.

Yang F., Shah S. L., \& Xiao D. Y. (2012). Signed directed graph based modelling and its validation from process knowledge and process data. Int. J. Appl. Math. Comput. Sci., vol. 22, no. 1, pp. 41-53.
Yang Z. L., Wang B., Dong X. H., \& Liu H. (2012). Expert system of fault diagnosis for gear box in wind turbine. Systems Engineering Procedia, vol. 4, pp. 189-195.

Zhang X., \& Pisu P. (2014). An unscented Kalman filter based on-line diagnostic approach for PEM fuel cell flooding. International Journal of Prognostics and Health Management 1(5).

\section{BIOGRAPHIES}

Yufei Lin is a $\mathrm{PhD}$ candidate in School

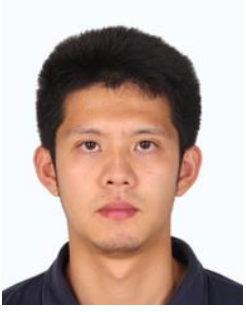

of Aerospace, Transport and Manufacturing, Cranfield University, UK. He received his B.Sc. degree in Automation from Shanghai Jiao Tong University in 2011 and M.Sc. degree in Control Theory and Control Engineering from Tsinghua University, Beijing, China. His research interests include fault diagnosis and Bayesian statistics.

Dr. Zakwan Skaf leads the research of diagnostics and prognostics in the Cranfield IVHM Centre, He is the Course Director of the Introduction to Integrated Vehicle Health Management (IVHM) short course and Module Leader of Diagnostics and Prognostics for the MSc Through-life System Sustainment course at Cranfield University. He received the B.S. degree from the faculty of Mechanical Engineering in 2001, and the MSc and Ph.D. degrees from the University of Manchester, Control Systems Centre, Manchester, U.K., in 2006 and 2011 respectively. His research interest involves control engineering, diagnostics, and prognostics related to aerospace, railway, and automotive applications.

Prof. Ian K Jennions is Director of the IVHM Centre at

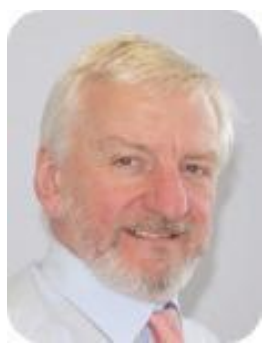
Cranfield University. He has over 30 years of industrial experience working in engineering and service. He has a Mechanical Engineering degree and a $\mathrm{PhD}$, both from Imperial College, London. He moved to Cranfield in 2008 as Professor and Director of the newly formed IVHM Centre, and has led the development and growth of the Centre, in research and education. Ian is on the editorial Board for the International Journal of Condition Monitoring, a Director of the PHM Society, vice-chair of the SAE IVHM Steering Group and contributing member of the HM1 IVHM committee, a Chartered Engineer and a Fellow of IMechE, RAeS and ASME. He is the editor of five recent SAE books on IVHM and a co-author of the book: 'No Fault Found - The Search for the Root Cause'. 